\title{
Improving Efficiency of Power Systems by Demand Side Management Method
}

\author{
Tibbie Pon Symon V. A. ${ }^{1}$, I. Jacob Ragland ${ }^{2}$ \\ ${ }^{1}$ Noorul Islam University, Tamil Nadu 629180, India \\ ${ }^{2}$ VIT, Vellore, Tamil Nadu, India
}

\begin{tabular}{l}
\hline Article Info \\
\hline Article history: \\
Received Oct 22, 2016 \\
Revised Jan 7, 2017 \\
Accepted Jan 21, 2017 \\
\hline
\end{tabular}

\section{Keyword:}

Demand side management Home area network Deregulated power system Smart grid Particle swarm optimization

\begin{abstract}
In the smart grid infrastructure based power systems, it is necessary to consider the demand side management to enhance the energy reduction and system control. In many countries the resources are very less so the available resources have to be used in an efficient manner without any loss. The total loss cannot be avoided but it can be reduced. In the proposed system, the Particle Swarm Optimization (PSO) technique is used to distribute the power in the smart grid. Here, the grids are arranged in such a way that the losses in it are reduced. The load connected to the grid is rearranged according to their use. It uses a new and stochastic scheduling technique to handle the uncertainties in the power system. Solar and wind power are taken in account for twenty four hours and the values are given to the PSO algorithm. The experiment was conducted by MATLAB and the results show that the efficiency level of wind and solar power systems was increased by an appreciable level. The proposed technique is compared with the normal system without using Demand Side Management (DSM) and it shows that the proposed system gives better results than the existing systems.
\end{abstract}

Copyright $\odot 2017$ Institute of Advanced Engineering and Science. All rights reserved.

\section{Corresponding Author:}

Tibbie Pon Symon V. A.,

Departement of Electrical and Electronics Engineering,

Noorul Islam University,

Tamil Nadu -629180, India.

Email: tibbiesymon@gmail.com

\section{INTRODUCTION}

The complexity of the electrical grid and electric power system infrastructure is growing with the increase of load demands. In many countries, the utility grids are source defined centralized power distribution systems [1]. The smart grid is a developing area and lot of research and experiments can be done in the paper design and also in the laboratories. [2], [3]. The main problem faced by the power system is that the loss in the distribution system, because the load is not same. Some of the load may be inductive, capacitive, purely resistive or the combination of these loads. The power consumption of load will differ based on the requirement of an application. Faults in the connected load can also cause loss in the power system. The generation and distribution system is challenged due the dynamic increase in the energy demand and the spontaneous rise in the global emission of green home gases. The grid is a complex operator consisting of different input loads like solar, thermal, wind etc., connected together.

The losses in the grid occur due to in mainly due to the improper arrangement of the infrastructure in the distribution side. The main reason of losses in the power grid is due to different consumers. The power taken by the consumer is usually more in the peak time and some of the grids may take more than the rated value. One of the reasons for the power loss is due to the consumers who are not having well awareness about the importance of energy. The consumer habits can be changed by awareness-raising programs which are often conducted by government or activist groups. Simple things to be done are turning off lights in 
disused rooms or switching off the television at night and task settings such as laundry for non-peak hours. New technologies will be added in the power grid for meeting the demands in future. In the power stations the latest and more flexible grid management methods will meet the increasing proportion of the renewable energy sources with conventional infrastructures associated.

Reducing the resource consumption is one of the important parameters. Day by day, the natural resources are reducing but the renewable energy is still available and that should be used in an efficient manner. Many countries are now using the renewable energy resources like wind and solar energy more efficiently. The major disadvantage of this renewable energy is that the wind will not be there for long time and the sun will not shine for the whole day. Most of the developed countries use these noise and pollution free renewable energy resources.

The high demand during peak time is managed by the DSM by activating the supplementary power generation source [4], [5]. The reliability of the grid is increased by setting a threshold value for each consumer under a grid. If the reliability of the grid is increased then the reliability of the whole power system will also be increased. When the supplementary power is given for the high power consumers it will not affect the low power consumers. But, it leads additional maintenance and care for the newly added supplementary power supply. It also leads to the power loss and money loss [6]. The supplementary power supply needs the additional power suppliers or generating plants that are infrequently turned on. When the power is generated from micro turbines or gases or to be imported from other countries then the cost will be increased.

The smart grid allows the consumers to elegantly consume electricity both by selecting the preferred suppliers and scheduling the operations of each appliance according to the various conditions. Now DSM is one of the important concerns to meet the consumer requirements as well as to achieve the system goals such as peak load reduction, power saving, energy efficiency, time saving, low cost etc. [7], [8]. Now a day the load increasing is in a spontaneous manner. Even the auto motive vehicles and trains are also be changed as electrically operated. The power demand is increased due to the Plug in hybrid electric vehicles (PHEV) that are introducing in the market.

In some cases, the efficient delivery will not be possible due to the complex network. But this can be achieved by using more advanced devices and technologies. Another way is by scheduling the power among the grids as well as the distribution system. But, this type of scheduling will make much disturbance for the consumers. To avoid these problems, a Particle Swam Optimization (PSO) technique is used instead of power scheduling. PSO is applied in widely in the area for problem solving. This PSO algorithm is based on the activities of a group of animals which does not have any organizer in their group. Here, the group of animals will not have any leader and they will randomly find out their food by following a member of their group with the nearby location from the food. This is a type of potential solution for the problem. The members of the group attain the best condition concurrently by making the communication between the group members who already have a better condition. These members will intimate it to the group then they will also go to that place. This process will be repeated until the best solution or a food source is found out [9], [10].

\section{PROPOSED TECHNIQUE}

In the proposed PSO system, the solar power and the wind power are considered. These values are taken by assuming that the consumers consume their maximum connected capacity. Furthermore, in this proposed PSO based system, the automatic scheduling solution result within ten seconds which is fast enough for the smart grid to schedule the power [11]. The architecture of the proposed PSO technique is depicted in Figure 1. It uses micro generation model which consists of various sources like wind turbines, solar cells and batteries [12-15]. This combination of the different sources together leads to a new design of Hybrid Renewable Energy System (HRES) [16]. The PSO is connected with the power grid and the consumers. Here, PSO is taken as a control system tool to optimize the power scheduling in the smart grid. The generated power for each hour in a day is calculated and given as input to the PSO. The excess power is used to charge the battery. If the consumers need more power at peak time the battery will act as the supplementary source.

In this HRES a battery is used to meet either the high power demand or when the renewable energy sources are not available [17]. The periodic nature of renewable energy makes the fluctuations that are unpredictable and appears in the power output [18]. Some of the storage techniques like batteries, compressed air, fly wheels and capacitors are used to solve these problems [19]. The battery can be recharged by taking the energy from different power generations and renewable sources. Therefore a balanced optimization technique is needed to meet the stability of the utilization of energy from renewable energy sources and recharging the battery source. 
The flowchart of the proposed work is given in Figure 2. Once all the required parameters like cost rate and generated power from the solar and wind for each hours in a day are collected, they will be given as the input to the PSO algorithm. Then the cost and power consumption by the consumers for 24 hours are calculated and displayed. The iterations are repeated and the best value will be selected as the threshold by the algorithm for each hour. If the threshold value is obtained during early stages of iterations then the iteration will be stopped in that hour.

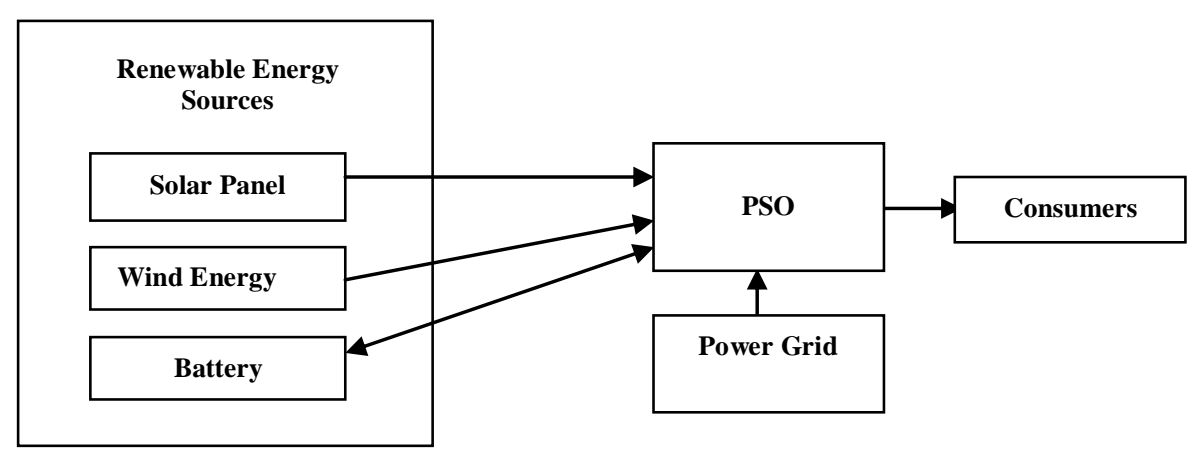

Figure 1. Architecture of HRES

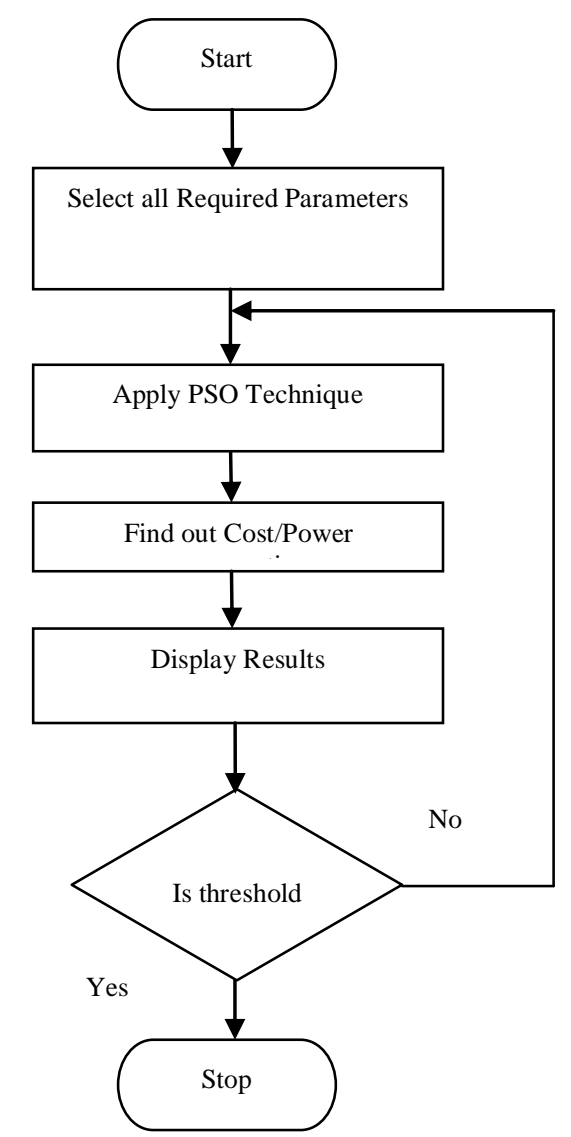

Figure 2. Flowchart of the Proposed Work

\section{RESEARCH METHOD}

The proposed technique is designed on the basis of the demand side management (DSM). It will either shift requirement from peak time to off - peak time or shrink the electricity peak demand [20]. The used tool can also monitor all the consumers as well as appliances connected in the houses. 
The problem solving in the PSO algorithm are done as follows:

Consider a function $\mathrm{F}(\mathrm{x})$, where

$$
\mathrm{F}(\mathrm{x})=(\mathrm{E}-((1-\mathrm{i}) *(\mathrm{PV}+\mathrm{WE}))) * \mathrm{CR}
$$

Here, i represents the optimization parameter

$\mathrm{E}=$ total power consumed by the appliances

$\mathrm{CR}=$ cost rate

$\mathrm{PV}=$ solar energy

$\mathrm{WE}=$ wind energy

The amount of energy to charge the battery at any instant is given in the following equaion

$$
i^{*}(\mathrm{PV}+\mathrm{WE})
$$

The difference between maximum capacity of the battery and the amount available for the given instant during the recharge

$$
\mathrm{G}(\mathrm{x})=\mathrm{E}_{\mathrm{b}}-\left(\mathrm{E}_{\mathrm{ba}}+\mathrm{i} *(\mathrm{PV}+\mathrm{WE})\right)
$$

$\mathrm{E}_{\mathrm{b}}=$ the maximum battery capacity

$\mathrm{E}_{\mathrm{ba}}=$ the maximum energy during the calculation

At any instance, the value of ' $\mathrm{i}$ ' is a percentage value and it lies between the limits $0 \leq \mathrm{i} \leq 1$

During the recharging $G(x) \geq 0$

$$
\text { i.e } \quad E_{b}-\left(E_{b a}+i *(P V+W E)\right) \geq 0
$$

\section{RESULTS AND DISCUSSION}

The values of energy produced in each hour of a day for wind as well as in solar plant are given in Table 1 and Table 2 MATLAB is used for the simulation. Table 1 gives the values for wind energy and Table 2 is for solar energy.

Table 1. Wind Energy from Wind Farm

\begin{tabular}{cc}
\hline Hour of Duty in a day & $\begin{array}{c}\text { Generated power } \\
(\mathrm{W} / \mathrm{m} 2)\end{array}$ \\
\hline 1 & 45.1 \\
2 & 16.7 \\
3 & 5.7 \\
4 & 34.6 \\
5 & 20.8 \\
6 & 27.2 \\
7 & 36.8 \\
8 & 12.2 \\
9 & 6.5 \\
10 & 37.6 \\
11 & 3.00 \\
12 & 31.6 \\
13 & 19.7 \\
14 & 44.2 \\
15 & 11.3 \\
16 & 11.4 \\
17 & 13.7 \\
18 & 27.6 \\
19 & 34.9 \\
20 & 20.9 \\
21 & 31.1 \\
22 & 3.24 \\
23 & 35.1 \\
24 & 2 \\
\hline & \\
\hline
\end{tabular}

Table 2. Solar Energy from Solar Plant

\begin{tabular}{cc}
\hline Hour of Duty in a day & $\begin{array}{c}\text { Generated power } \\
(\mathrm{W} / \mathrm{m} 2)\end{array}$ \\
\hline 1 & 0 \\
2 & 0 \\
3 & 0 \\
4 & 0 \\
5 & 0 \\
6 & 0 \\
7 & 57 \\
8 & 215 \\
9 & 346 \\
10 & 703 \\
11 & 956 \\
12 & 1045 \\
13 & 988 \\
14 & 948 \\
15 & 898 \\
16 & 788 \\
17 & 580 \\
18 & 351 \\
19 & 76 \\
20 & 0 \\
21 & 0 \\
22 & 0 \\
23 & 0 \\
24 & 0 \\
& \\
\hline
\end{tabular}

The PSO algorithm will go for a number of iterations and it will give out the best result. The values taken from the wind and the solar plants are entered into the PSO algorithm and it will calculate the better 
one from the function Equation 1, where ' $i$ ' is the optimization parameter. After the iterations are over the efficiency of smart grid and the connected load is calculated. The input which is given to the PSO is given in Figure 3 and the efficiency output generated from the PSO is given in Figure 4.

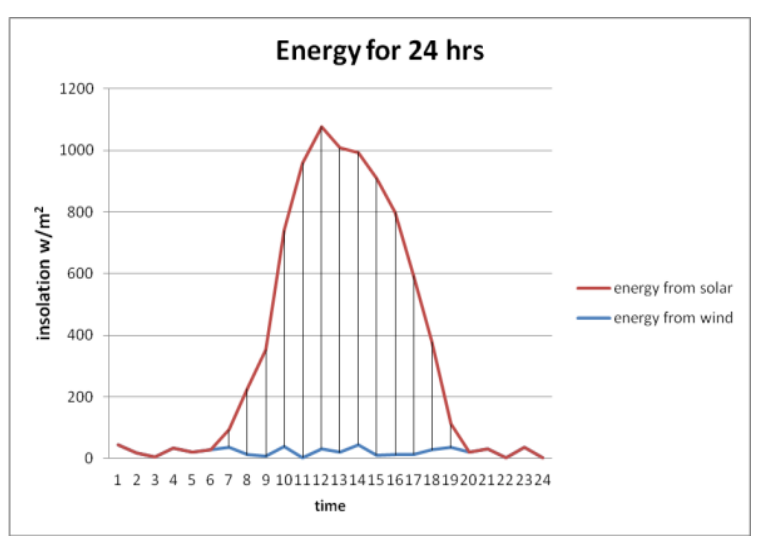

Figure 3. Input to the PSO

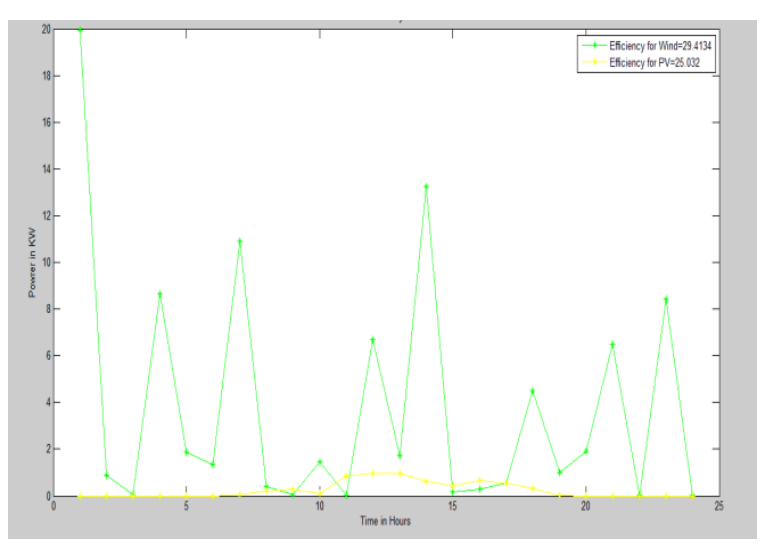

Figure 4. Efficiency output by PSO

The overall performance output from the PSO is given in Figure 5. The proposed work with DSM is compared with the existing one without DSM and the values are given in Table 3. It gives the performance output for the 24 hours for wind and solar with DSM and without DSM. The PSO output for the Table 3 is given in Figure 6.

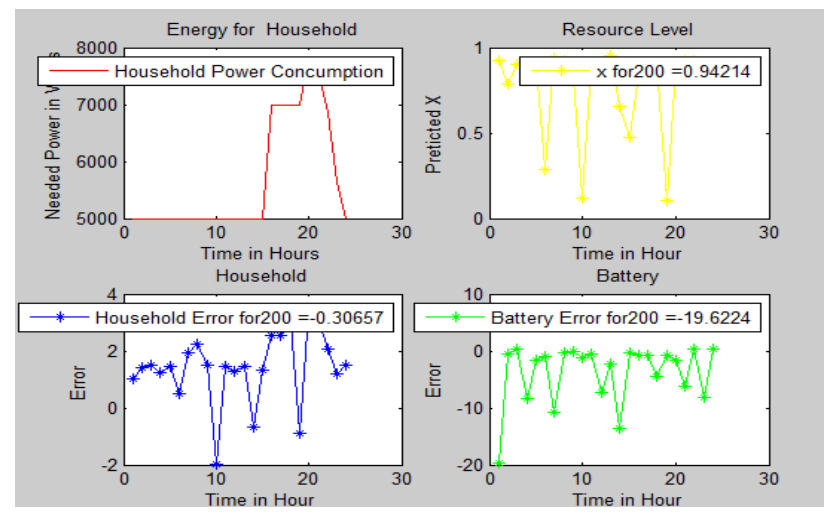

Figure 5. Overall Performance Output from PSO

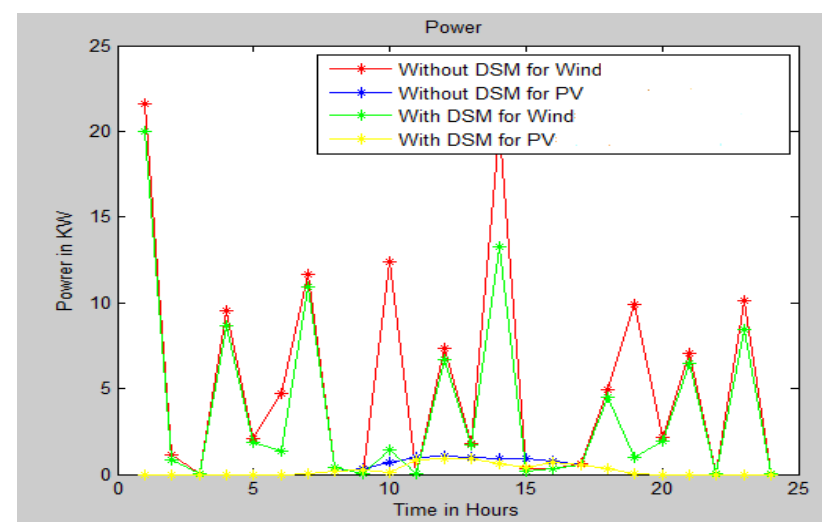

Figure 6. Comparison of proposed and normal system 
Table 3. Values with DSM and without DSM

\begin{tabular}{ccccc}
\hline $\begin{array}{c}\text { Hours in a } \\
\text { day }\end{array}$ & $\begin{array}{c}\text { Wind without DSM } \\
(\mathrm{KW})\end{array}$ & $\begin{array}{c}\text { Wind with } \\
\text { DSM(KW) }\end{array}$ & $\begin{array}{c}\text { Solar without DSM } \\
(\mathrm{KW})\end{array}$ & $\begin{array}{c}\text { Solar with } \\
\text { DSM(KW) }\end{array}$ \\
\hline 1 & 21.5705 & 19.9571 & 0 & 0 \\
2 & 1.1076 & 0.8703 & 0 & 0 \\
3 & 0.0480 & 0.0434 & 0 & 0 \\
4 & 9.5087 & 8.6407 & 0 & 0 \\
5 & 2.0718 & 1.8670 & 0 & 0 \\
6 & 4.7006 & 1.3426 & 0 & 0.0524 \\
7 & 11.6409 & 10.8961 & 0.056 & 0.1982 \\
8 & 0.4242 & 0.3929 & 0.214 & 0.2881 \\
9 & 0.0604 & 0.0534 & 0.356 & 0.0824 \\
10 & 12.4168 & 11.4552 & 0.703 & 0.8601 \\
11 & 0.0063 & 0.0052 & 0.955 & 0.9486 \\
12 & 7.3707 & 6.6971 & 1.044 & 0.9445 \\
13 & 1.7855 & 1.7056 & 0.989 & 0.6226 \\
14 & 20.1703 & 13.2330 & 0.949 & 0.4255 \\
15 & 0.3370 & 0.1595 & 0.899 & 0.6726 \\
16 & 0.3461 & 0.2950 & 0.789 & 0.05340 \\
17 & 0.6006 & 0.5520 & 0.58 & 0.3235 \\
18 & 4.9110 & 4.5134 & 0.352 & 0.0075 \\
18 & 9.9294 & 1.015 & 0.073 & 0 \\
20 & 2.1325 & 1.9208 & 0 & 0 \\
21 & 7.0262 & 6.5047 & 0 & 0 \\
22 & 0.0079 & 0.0074 & 0 & 0 \\
23 & 10.1010 & 8.4190 & 0 & 0 \\
\hline
\end{tabular}

\section{CONCLUSION}

In the proposed work, PSO technique is used for the development and testing of the consumer based DSM. The smart grid can be operated in more efficient and reliable way and the power losses can be reduced. It gives an excellent performance in the system as well as possible benefits for DSM. It also allows the consumer to select the appliances and manage the resources in an optimized manner. The results from the PSO simulation achieve an average of $28 \%$ of cost saving for the end-user. These results lead to considerable annual savings for the consumers. This PSO totally reshuffle the grid system by choosing the most efficient way and gives accurate result. It is used to extend and improve the research in the power system as well as the grids. This work can be modified in the future by comparing the results with the cuckoo search algorithm or other algorithms like fire fly, bat, or ant colony.

\section{REFERENCES}

[1] N. Gudi, et al., "A Demand Side Management Based Simulation Platform Incorporating Heuristic Optimization for Management of Household Appliances," Electrical Power and Energy System, Science Direct, vol. 43. pp. 185193, 2012.

[2] "The Smart Grid: An Introduction," 2008. http://www.oe.energy.gov/SmartGrid Introduction.htm.

[3] D. Zang, et al., "Efficient Energy Consumption and Operation Management in a Smart Building with Microgrid," Energy Conservation and Management, vol. 74, pp. 209-222, 2013.

[4] Clastres, "Smart Grids: Another Step towards Competition, Energy Security and Climate Change Objectives," Energy Policy, vol. 5, pp. 399-408, 2011.

[5] N. Gudi and L. Wang, "A demand side management based simulation platform incorporating heuristic optimization for management of household appliances," Electrial power energy systems, vol. 43, pp. 185-193, 2012.

[6] P. Bunnoon, "Fault Detection Approaches to Power System: State-of-the-ArtArticle Reviews for Searching a New Approach in the Future," International Journal of Electrical and Computer Engineering, vol/issue: 3(4), pp. 553 560, 2013.

[7] J. M. Armas and S. Suryanarayanan, "A Heuristic Technique for Scheduling a Customer Driven Residential Distributed Energy Resource Installation," Proc. 15 $5^{\text {th }}$ International Conference on Intelligent Systems Applications to Power Systems, pp. 1-7, 2009.

[8] Rand D. and Dell R., "Energy Storage: A Key Technology for Global Energy Sustainability,” Journal of Power Source, vol/issue: 100(1), pp. 2-17, 2001.

[9] D. Palupirini, et al., "Particle Swam Optimization: Technique, System and Challenges," International Journal of Computer Application, vol. 4, 2011.

[10] Valle Y. D., et al., "Particle swarm optimization: basic concepts, variants and applications in power systems," IEEE Transactions on Evol. Computing, vol/issue: 12(2), pp. 171-195, 2008.

[11] M. Khanabadi, et al., "Optimal Transmission Switching Considering Voltage Security and N-1 Contigency Analysis," IEEE Transactions on Power Systems, vol/issue: 28(1), 2013. 
[12] Watson J., "Co-provision in Sustainable Energy Systems: The case of Microgeneration,” Energy Policy, vol/issue: 32(17), pp. 1981-90, 2004.

[13] H. Shahinzadeh, et al., "Applications of Particle Swarm Optimization Algorithm toSolving the Economic Load Dispatch of Units in Power Systems with Valve-Point Effects," International Journal of Electrical and Computer Engineering, vol/issue: 4(6), pp. 858-867, 2014.

[14] J. J. Jamian, et al., "Implimentation of Evolutionary Particle Swarm Optimization in Distributed Generation Sizing," International Journal of Electrical and Computer Engineering, vol/issue: 2(1), pp. 137-146, 2012.

[15] F. Yusivar, et al., "Single Phase PV Grid-Connected in Smart Household Energy System with Anticipation on Fault Conditions," International Journal of Power Electronics and Drive System (IJPEDS), vol/issue: 4(1), pp. 100 111, 2014.

[16] Deshmukh M. K. and Deshmukh S. S., "Modeling of Hybrid Renewable Energy Systems," Renewable Sustain Energy, vol/issue: 12(1), pp. 235-49, 2008.

[17] Hajizadeh A. and Golkar M. A., "Intelligent Power Management Strategy of Hybrid Distributed Generation System," Electrical Power Energy System, vol. 29, pp. 783-95, 2007.

[18] Anderson D. and Leach M., "Harvesting and redistributing renewable energy: On the role of gas and electricity grids to overcome intermittency through the generation and storage of hydrogen," Energy Policy, vol/issue: 32(17), pp. $1603-13$.

[19] Dell R. and Rand D., "Energy storage: A key technology for global energy sustainability," Journal of Power Source, vol/issue: 100(1), pp. 2-17, 2001.

[20] National solar radiation data base, 2010. http://rredc.nrel.gov/solar/old_data/nsrdb/.

\section{BIOGRAPHIES OF AUTHORS}
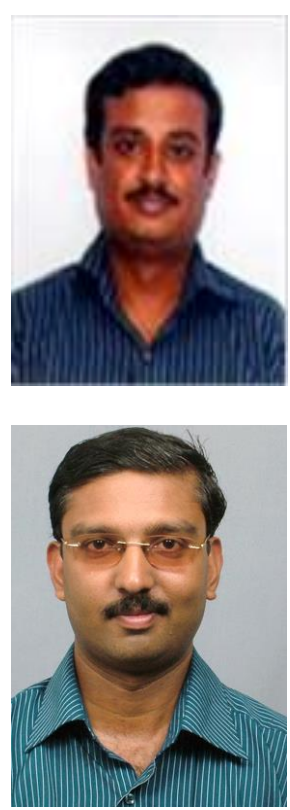

Tibbie Pon Symon.V.A received a Bachelor of Technology in Electrial and Electronics Engineering from Kannur University, Kerala, India in 2001, a Master of Engineering in Power Electronics from Karunya University, India. Now he is working as an Assistant professor in the department of Electrical and Electronics Engineering at Noorul Isalm University and doing PhD in Noorul Islam University, India, Tamil Nadu, India. His area of interest is Power System and Power Electronics.

Dr. I. Jacob Raglend received his Bachelors degree in Electrical Engineering from The Indian Engineering College and the Masters degree in Power Systems Engineering from Annamalai University with first class in 2000 and 2001 respectively. He has done his Ph.D. degree in the Department of Electrical and Electronics Engineering, Indian Institute of Technology, Roorkee, India in the year 2007. Presently he is working as a Professor in the School of Electrical Engineering, Vellore Institute of Technology (VIT) India. He taught course in Basic Electrical Engineering, Power Systems, Artificial Intelligence and Soft Computing Techniques. His field of interest is Unit Commitment, Economic Dispatch, Smart Grid, Power System Restructuring and Deregulation, Artificial Intelligence Applications to Power System and FACTS. 